\title{
Effect of $\alpha$-tocopherol megadoses on hematologic parameters and antioxidant capacity of rats in an ultraendurance probe
}

\section{VJ Clemente-Suárez ${ }^{1}$, J Mielgo-Ayuso ${ }^{2}$, JL Quiles $^{3}$, A Varela-Lopez $^{3}$, P Aranda ${ }^{4}$}

\author{
${ }^{1}$ Applied Psychophysiological Research Group, European University of Madrid, Madrid, Spain \\ ${ }^{2}$ Infine Research Group, Department of Health and Sport Performance, INEF, Polytechnic University of Madrid, \\ Madrid, Spain \\ ${ }^{3}$ Department of Physiology, Biomedical Research Center, Institute of Nutrition and Food Technology "Jose Mataix", \\ University of Granada, Granada, Spain \\ ${ }^{4}$ Faculty of Pharmacy, Department of Physiology, University of Granada, Granada, Spain
}

Received: February 21, 2017

Accepted: November 2, 2017

This study was aimed to analyze the effect of two different megadoses of $\alpha$-tocopherol (vit E) in the antioxidant activity and red and white blood series of Wistar rats after a 180-min ultraendurance probe. Three groups of 10 rats were analyzed; VEAG: acute administration of a megadoses of 5,000 IU/kg of vit E the day before the probe; VECG: chronic administration of 1,000 IU/kg/day of vit $\mathrm{E}$ for 6 days before the probe; CG: placebo administration. VEAG presented white cells, red blood cells, hematocrit, hemoglobin values significantly higher than CG and VECG $(p<0.05)$. The mean corpuscular hemoglobin and lymphocytes concentrations were significantly higher in the VECG than in the other two groups $(p<0.05)$. Similarly, VEAG presented a significantly higher vit E blood concentration than VECG and CG $(p<0.05)$, and VECG than CG $(p<0.05)$. Finally, we found a significantly positive correlation between trolox equivalent antioxidant capacity (TEAC) and red blood cells concentration $(r=0.374)$ and a significantly inverse correlation between TEAC and blood lactate concentration $(r=-0.365)$. Our findings suggest that acute vit E megadoses could protect against transitory sport anemia symptoms and increase the white blood cell count in comparison with the chronic dose and control groups after an ultraendurance probe.

Keywords: vitamin E, ultraendurance, antioxidant capacity, sport anemia, wistar rat, white blood cell, red blood cell, running performance

\section{Introduction}

The popularity and increased participation in ultraendurance probes in past years have produced an important increase in the number of participants in these events (5). Due to their long duration, these probes present special demands on human physiology, causing hematological and biochemical alterations in the participants (37). It was measured that increments in maximal oxygen uptake in ultraendurance probes increase the production of reactive oxygen species (ROS) and reactive nitrogen species (RNS), and this increase depends on the type of the exercise conducted and the physical fitness of athletes $(20,22)$. This increase could exceed the capacity of organic antioxidant systems, producing an increase in oxidative stress resulting in peroxidation (damage) of polyunsaturated fatty acids in the cell membranes,

\footnotetext{
Corresponding author: Vicente J. Clemente-Suárez

Applied Psychophysiological Research Group, Sport Sciences School, European University of Madrid

C/Tajo, s/n, Villaviciosa de Odón, Madrid 28670, Spain

Phone: +34 902232 350; Fax: +34 911413 585; E-mail: vctxente@yahoo.es
} 
proteins, and DNA nucleic acids $(7,35)$. Protein and lipid peroxidation cause changes in cell membrane integrity, eliciting inflammation and decreasing the ability of the cell to maintain ion gradients, facilitating cellular dehydration. Hence, the importance of ROS and RNS as signals in the cellular adaptation process to stress is now evident $(15,19)$.

The erythrocytes are susceptible to oxidative stress during intense exercise due to their continuous exposure to oxygen and their high content of polyunsaturated fatty acids and hemo iron (28). The most common alterations in erythrocytes caused by oxidative stress are related to the peroxidation of membrane lipids and proteins that destabilize the membrane skeleton, compromising cell survival (15). Thus, an increase in the rigidity, cross-linking of protein-lipid fractions, or changes in the membrane permeability of erythrocytes generate hemolysis $(3,6)$, suggesting a relationship between oxidative stress and iron metabolism (1). Specifically, ultraendurance athletes experienced a reduction in hematological parameters, such as hematocrit, hemoglobin, and serum iron, causing the "athlete's anaemia" (1). In addition, an increase in lipid peroxidation has been observed in erythrocytes after strenuous acute treadmill exercise in both rats and humans (17). It has also been proved that these probes caused a modification in the leukocyte count (37) because of an inflammatory response (1).

The supplementation with antioxidants such as vitamin $E$ ( $\alpha$-tocopherol) and its potential buffering effect against exercise-induced ROS have attracted the researchers' interest in recent years. The results show conflicting data regarding the effects of $\alpha$-tocopherol administration in various oxidative stress parameters $(22,35)$. Some authors have found that exogenous $\alpha$-tocopherol administration for several weeks increased the activity of antioxidant enzymes, such as glutathione peroxidase and catalase, thereby reducing oxidative stress and preventing lipid peroxidation, inflammation, and DNA damage $(10,32,33)$. On the other hand, other studies have not shown improvements in these parameters (14, 21). Similarly, excepting the exercise at high altitude (where oxidative stress is compounded), ergogenic effects after the $\alpha$-tocopherol supplementation have not been shown in endurance sports (34). All these investigations used chronic administration (weeks or months) of vitamin E doses that did not exceed 1,200 IU/day. However, there are no studies with higher doses or using acute administrations.

Due to the lack of studies on the administration of acute $\alpha$-tocopherol megadoses, especially in ultraendurance probes in which the ROS production is increased (3), this research was proposed with the principal aim of studying the effects of an acute megadose of $5,000 \mathrm{IU} / \mathrm{kg} \alpha$-tocopherol the day before and chronic administration of $1,000 \mathrm{IU} / \mathrm{kg} / \mathrm{day}$ $\alpha$-tocopherol for 5 days before a 180-min ultraendurance running probe on the antioxidant activity, red, and white blood series of Wistar rats. As a secondary objective, we studied the influence of $\alpha$-tocopherol megadoses on food ingestion prior to the probe.

\section{Materials and Methods}

\section{Experimental approach to the problem}

An experimental study was performed. Variables of red blood cell, hemoglobin, hematocrit, mean cell volume, mean cell hemoglobin, mean cell hemoglobin concentration, lymphocytes, neutrophils, monocytes, trolox equivalent antioxidant capacity (TEAC), $\alpha$-tocopherol, and lactate were evaluated after a 180-min ultraendurance running probe in three different groups of Wistar rats: vitamin E acute dose group (VEAG): administration of 5,000 UI/ $\mathrm{kg} 1$ day 
before the probe; Vitamin E chronic dose group (VECG): administration of 1,000 UI/kg/day for 5 days prior to the probe; and control group (CG): administration of bidistilled water for 5 days before the probe. In addition, daily food ingestion was evaluated in each group.

\section{Experimental protocol}

Thirty male Wistar rats (Ratus novergicus) with an initial average weight of $184.0 \pm 10.8 \mathrm{~g}$ were analyzed. The rats were randomly divided into three experimental groups of 10 rats. The VEAG received a dose of $5 \mathrm{ml}$ of bidistilled water (placebo) for 4 days prior to the probe and the day before the probe they received a dose of 5,000 UI/kg of vitamin $\mathrm{E}$ (acetate dl- $\alpha$-tocopherol, CHIESI SPAIN SA) (31) mixed with $0.5 \mathrm{ml}$ of bidistilled water. The VECG received a dose of $1,000 \mathrm{IU} / \mathrm{kg}$ of vitamin $\mathrm{E}$ (acetate dl- $\alpha$-tocopherol, CHIESI SPAIN SA) (38) mixed with $0.5 \mathrm{ml}$ of bidistilled water for 5 days prior to the ultraendurance probe. The $\mathrm{CG}$ received a dose of $5 \mathrm{ml}$ of bidistilled water (placebo) for 5 days before the ultraendurance probe. For the administration of both placebo and vitamin E, an endotracheal tube was used.

During the entire experimental period, the rats were kept in individual metabolism cages that allowed the motorization of food intake to analyze possible changes caused by the administration of corresponding doses of vitamin $\mathrm{E}$. The cages were placed in a thermoregulated $\left(22 \pm 2{ }^{\circ} \mathrm{C}\right)$, properly ventilated room with controlled $12 \mathrm{~h}$ photoperiod. All rats consumed an AIN93-M diet that covered their daily dietary needs, and ate and drank ad libitum before the probe. Food ingestion and weight changes are shown in Table I.

Prior to the probe, all rats performed a treadmill adaptation in the treadmill used later in the 180 -min probe. This adaptation consisted of two series of 5 min running at $25 \mathrm{~cm} / \mathrm{s}$ and $5 \mathrm{~min}$ running at $30 \mathrm{~cm} / \mathrm{s}$ carried out on two consecutive days. After the adaptation to the treadmill, rats rested 1 day before they performed a maximal incremental running test in the treadmill to obtain their maximal oxygen uptake $\left(\mathrm{VO}_{2 \mathrm{max}}\right)$. The protocol used was as follows (11): $5 \mathrm{~min}$ warm up at 25 and $3 \mathrm{~cm} / \mathrm{s}$ speed increments each minute till exhaustion. After obtaining the $\mathrm{VO}_{2 \max }, 60 \%$ of $\mathrm{VO}_{2 \max }$ running speed was calculated. This $\mathrm{VO}_{2 \max }$ percentage is the intensity measured in slower marathon runners who conducted this probe (13). This intensity was

Table I. Food ingestion and weight gain of rats

\begin{tabular}{|l|c|c|c|}
\hline & CG & VEAG & VECG \\
\hline Day 1 & $19.61 \pm 5.23$ & $21.77 \pm 7.16$ & $25.45 \pm 1.59$ \\
\hline Day 2 & $17.65 \pm 3.88$ & $19.03 \pm 1.95$ & $19.68 \pm 1.71$ \\
\hline Day 3 & $17.29 \pm 2.91$ & $16.24 \pm 5.12$ & $17.75 \pm 1.90$ \\
\hline Day 4 & $17.56 \pm 2.77$ & $13.9 \pm 3.92$ & $16.94 \pm 7.28$ \\
\hline Day 5 & $16.66 \pm 2.96$ & $14.93 \pm 5.05$ & $14.65 \pm 5.12$ \\
\hline Total & $88.76 \pm 14.26$ & $85.87 \pm 12.83$ & $94.46 \pm 10.84$ \\
\hline $\begin{array}{l}\text { Percentage of increase in } \\
\text { body weight }\end{array}$ & $37.48 \pm 9.76$ & $32.27 \pm 19.47$ & $43.11 \pm 5.81$ \\
\hline
\end{tabular}

CG: control group; VEAG: group with acute dose of vitamin E; VECG: group with chronic dose of vitamin E 
selected to perform the ultraendurance probe for rats as they were not specifically trained for ultraendurance running. After the $\mathrm{VO}_{2 \max }$ test, rats rested for 1 day, and then each rat performed the 180 -min probe at a treadmill velocity, which corresponded to $60 \%$ of the $\mathrm{VO}_{2 \max }$.

During the maximal incremental running test, oxygen uptake was analyzed with a gas analyzer model LE405 Panlab and the software V2.2.00 Metabolism, Panlab (Barcelona, Spain). The incremental test and the ultraendurance probe were performed on a treadmill Control Model LE8710 Panlab (Barcelona, Spain). The ultraendurance probe was individually performed by each rat in the treadmill. Immediately after completing the probe, rats were sacrificed by decapitation, and white blood cell count, red blood cell count, hemoglobin concentration, hematocrit, mean corpuscular volume, mean corpuscular hemoglobin, mean corpuscular hemoglobin concentration, and platelet and lymphocyte count of fresh blood samples treated with EDTA as anticoagulant were measured using an automated hematology analyzer Sysmex KX-21 (Sysmex Corporation, Kobe, Japan). The TEAC assay was carried out using a combination of a flow injection analysis system (4). Storing and analysis of samples for the determination of $\alpha$-tocopherol in plasma were assayed according to the method of MacCrehan (9) by reversed-phase HPLC with a Spherisorb S5 ODS1 (Merck, Darmstadt, Germany).

\section{Statistical analysis}

Data were analyzed using the Statistical Package for the Social Sciences (SPSS) version 17 (SPSS Inc., Chicago, IL, USA). The Shapiro-Wilk normality test was used to test homogeneity of each variable. For the variables that fulfilled the assumptions of normality and homoscedasticity, an independent one-factor analysis of variance with a Bonferroni post hoc test with the blood parameters as independent factors and the three rat groups as a factor was performed. For variables that did not fulfilled the assumptions of normality and homoscedasticity, the Kruskal-Wallis test was performed. Bivariate correlation analyses between TEAC and $\alpha$-tocopherol and other variables analyzed were performed using either Pearson's (parametric data) or Spearman's (non-parametric data) correlation analyses. The level of significance was set at $p<0.05$ for all the comparisons.

\section{Results}

None of the groups presented significantly differences in the daily food ingestion (Table I, Fig. 1). The results obtained after the ultraendurance probe show that VEAG presented white cells, red blood cells, hematocrit, and hemoglobin values significantly higher than the CG and VECG $(p<0.05)$. The mean corpuscular hemoglobin concentration was significantly higher in the VECG than in the other two groups. Values of leukocyte count showed that VECG had a significantly higher value of lymphocytes than VEAG and CG and also a significantly higher value of neutrophils. However, monocyte values did not significantly differ between the experimental groups, as well as TEAC values. However, VEAG presented a significantly higher $\alpha$-tocopherol blood concentration than VECG and CG. Simultaneously, VECG had a significantly higher $\alpha$-tocopherol blood concentration than CG (Table II). Finally, we found a weak, but significant correlation between TEAC and red blood cells concentration $(r=0.374$; $p=0.041)$ and also a weak, but significant inverse correlation between TEAC and blood lactate concentration $(r=-0.365 ; p=0.043)$. 

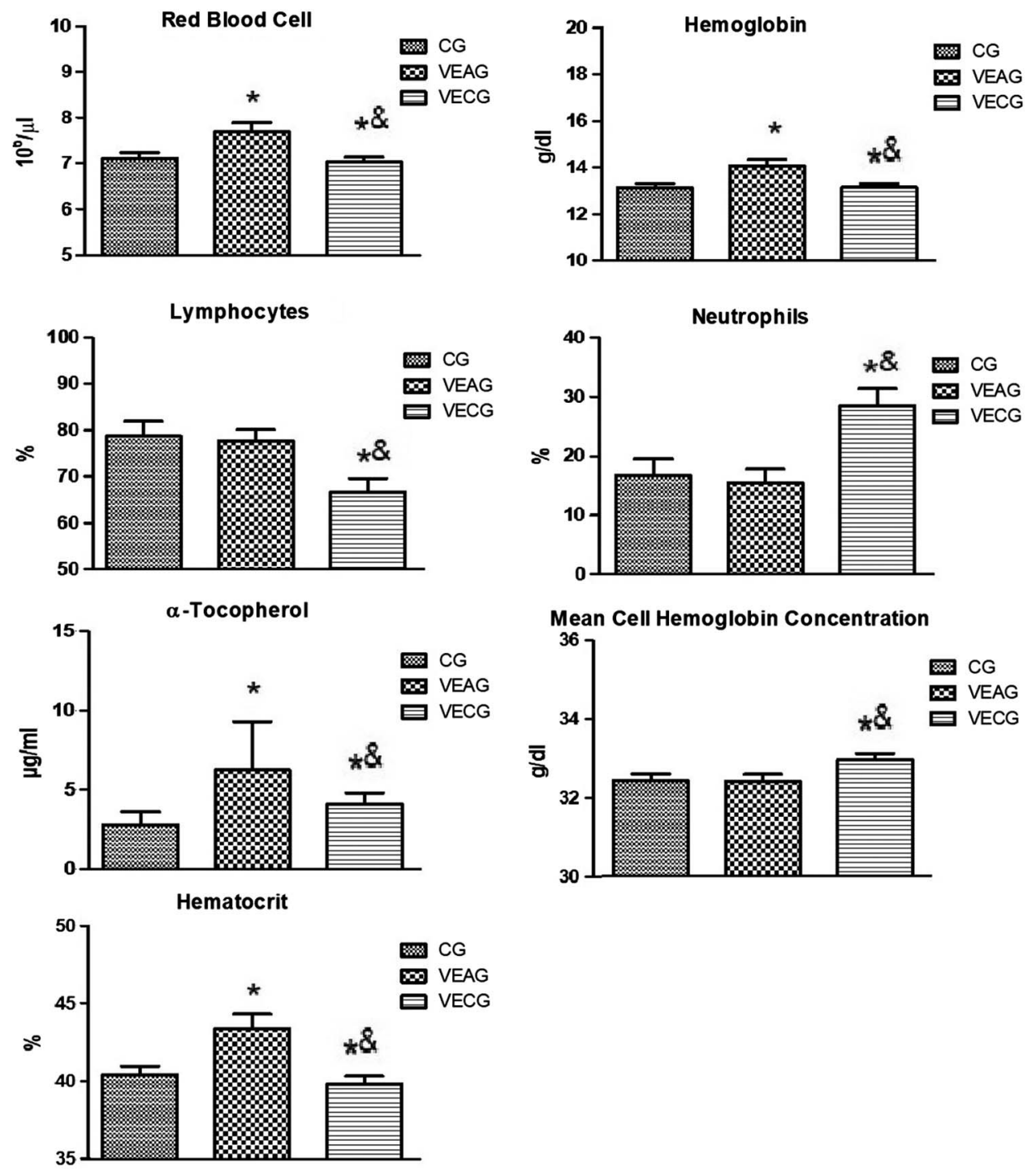

Fig. 1. Representation of hematological parameters. ${ }^{*} p<0.05$ versus CG; $\& p<0.05$ versus VEAG; CG: control group; VEAG: group with acute dose of vitamin E; VECG: group with chronic dose of vitamin E; TEAC: trolox equivalent antioxidant capacity

\section{Discussion}

The aim of the present research was to analyze the effect of the administration of an acute and a chronic $\alpha$-tocopherol megadose prior to an ultraendurance probe in the antioxidant activity, red and white blood series of Wistar rats. Results showed that the acute vitamin E megadose protected against transitory sport anemia symptoms and increased the white cell count in comparison with the chronic and CGs. 
Table II. Blood parameter data obtained after the ultraendurance race

\begin{tabular}{|c|c|c|}
\hline Parameter & Group & Values \\
\hline \multirow[t]{3}{*}{ Red blood cell $\left(10^{6} / \mu 1\right)$} & CG & $7.17 \pm 0.12$ \\
\hline & VEAG & $7.76 \pm 0.20^{\mathrm{a}}$ \\
\hline & VECG & $7.09 \pm 0.11^{\mathrm{a}, \mathrm{b}}$ \\
\hline \multirow[t]{3}{*}{ Hemoglobin (g/dl) } & $\mathrm{CG}$ & $13.25 \pm 0.18$ \\
\hline & VEAG & $14.22 \pm 0.29^{\mathrm{a}}$ \\
\hline & VECG & $13.26 \pm 0.18^{\mathrm{b}}$ \\
\hline \multirow[t]{3}{*}{ Hematocrit (\%) } & $\mathrm{CG}$ & $40.68 \pm 0.55$ \\
\hline & VEAG & $43.74 \pm 0.99^{\mathrm{a}}$ \\
\hline & VECG & $40.04 \pm 0.54^{\mathrm{a}, \mathrm{b}}$ \\
\hline \multirow[t]{3}{*}{ Mean cell volume (fL) } & CG & $56.81 \pm 0.39$ \\
\hline & VEAG & $56.44 \pm 0.56$ \\
\hline & VECG & $56.47 \pm 0.26$ \\
\hline \multirow[t]{3}{*}{ Mean cell hemoglobin (pg) } & CG & $18.51 \pm 0.18$ \\
\hline & VEAG & $18.36 \pm 0.22$ \\
\hline & VECG & $18.70 \pm 0.18$ \\
\hline \multirow{3}{*}{$\begin{array}{l}\text { Mean cell hemoglobin concentration } \\
(\mathrm{g} / \mathrm{dl})\end{array}$} & $\mathrm{CG}$ & $32.57 \pm 0.17$ \\
\hline & VEAG & $32.54 \pm 0.19$ \\
\hline & VECG & $33.12 \pm 0.17^{\mathrm{a}, \mathrm{b}}$ \\
\hline \multirow[t]{3}{*}{ White blood cell } & $\mathrm{CG}$ & $2.37 \pm 0.26$ \\
\hline & VEAG & $4.00 \pm 0.36^{\mathrm{a}}$ \\
\hline & VECG & $2.74 \pm 0.21$ \\
\hline \multirow[t]{3}{*}{ Lymphocytes (\%) } & $\mathrm{CG}$ & $79.60 \pm 3.34$ \\
\hline & VEAG & $78.55 \pm 2.60$ \\
\hline & VECG & $67.20 \pm 2.97^{\mathrm{a}, \mathrm{b}}$ \\
\hline \multirow[t]{3}{*}{ Neutrophils (\%) } & $\mathrm{CG}$ & $17.60 \pm 2.99$ \\
\hline & VEAG & $16.36 \pm 2.44$ \\
\hline & VECG & $30.00 \pm 3.17^{\mathrm{a}, \mathrm{b}}$ \\
\hline \multirow[t]{3}{*}{ Monocytes (\%) } & $\mathrm{CG}$ & $2.80 \pm 0.61$ \\
\hline & VEAG & $5.09 \pm 1.09^{\mathrm{a}, \mathrm{c}}$ \\
\hline & VECG & $2.80 \pm 0.85$ \\
\hline
\end{tabular}


Table II. Blood parameter data obtained after the ultraendurance race (Continued)

\begin{tabular}{|l|l|c|}
\hline \multirow{2}{*}{ Parameter } & \multicolumn{1}{|c|}{ Group } & Values \\
\hline \multirow{3}{*}{ TEAC $(\mu \mathrm{M})$} & CG & $134.60 \pm 11.40$ \\
\cline { 2 - 3 } & VEAG & $144.69 \pm 11.92$ \\
\cline { 2 - 3 } & VECG & $140.40 \pm 10.69$ \\
\hline \multirow{3}{*}{$\alpha$-tocopherol $(\mu \mathrm{g} / \mathrm{ml})$} & CG & $3.0 \pm 0.86$ \\
\cline { 2 - 3 } & VEAG & $6.65 \pm 3.26^{\mathrm{a}}$ \\
\cline { 2 - 3 } & VECG & $4.41 \pm 0.72^{\mathrm{a}, \mathrm{b}}$ \\
\hline \multirow{2}{*}{ Lactate $(\mathrm{mmol} / \mathrm{L})$} & CG & $2.14 \pm 0.83$ \\
\cline { 2 - 3 } & VEAG & $2.21 \pm 0.73$ \\
\cline { 2 - 3 } & VECG & $2.48 \pm 0.60$ \\
\hline
\end{tabular}

CG: control group; VEAG: group with acute dose of vitamin E; VECG: group with chronic dose of vitamin E; TEAC: trolox equivalent antioxidant capacity.

${ }^{a} p<0.05$ versus CG.

${ }^{\mathrm{b}} p<0.05$ versus VEAG.

${ }^{\mathrm{c}} p<0.05$ versus VECG

The ultraendurance events produced hemolysis by mechanical causes that increased capillary foot pressure in the impact phase of running and by the ROS increased production (23). Specifically, the ROS caused a decrease in erythrocyte membranes deformability, preventing its passage through the microcirculation and their proteo-lipid cross-linking; modifications in the membrane permeability of erythrocytes (3); and an initial oxidation of the hemo iron in different hemoglobin complexes (6). This hemolysis exceeds the erythropoiesis processes that are activated during ultraendurance races, causing a decline in red blood cells, hematocrit, and hemoglobin (24). The decrease of red blood cell count, hematocrit, and hemoglobin might cause a decrease in the athletes' performance by the appearance of transitory sports anemia (25). Therefore, the results of the present research showed that acute administration of 5,000 UI/ $/ \mathrm{kg} \alpha$-tocopherol megadose helps to mitigate the decline of these transitory sport anemia markers produced in ultraendurance events. The administration of vitamin $\mathrm{E}$ could help to maintain higher performance of ultraendurance athletes, protecting against the negative effects of ROS in hematological parameters. On the contrary, it seems that none of the $\alpha$-tocopherol doses used in this study appear to affect mean corpuscular volume and mean corpuscular hemoglobin.

Although the elevated blood level of $\alpha$-tocopherol is not necessarily an indicator of a higher intake of vitamin E, as it may also increase with age and lipids consumption (32), the data obtained support the hypothesis that a higher intake of vitamin E produces higher $\alpha$-tocopherol blood levels, since VEAG and VECG produced statistically higher $\alpha$-tocopherol levels than CG, without affecting the food intake. Furthermore, it has been shown that during an ultramarathon race, the amount of blood $\alpha$-tocopherol disappears faster than during a rest day, which also enhances lipid peroxidation (12). In this line, it has been found that the antioxidant supplementation (vitamins $\mathrm{C}$ and $\mathrm{E}$ ) for 6 months causes a significant increase in the blood level of $\alpha$-tocopherol prior to an ultramarathon, showing an inverse correlation between the levels of $\alpha$-tocopherol and blood levels of oxidative stress and lipid peroxidation (32). In addition, it is 
known that low levels of $\alpha$-tocopherol in human cause diverse degrees of hemolysis, depending on the age of the subject and the presence of other antioxidants (30). In the present research, we measured a better antioxidant capacity (TEAC) and higher serum $\alpha$-tocopherol levels in the VEAG than in the other two groups. This was associated with better values of anemia parameters, especially with the number of red blood cells.

The mean corpuscular volume, mean corpuscular hemoglobin, and mean corpuscular hemoglobin concentrations were similar in the three groups of rats. However, the number of red blood cells was lower in the CG and VECG. This fact is a symptom of transitory sports anemia, caused by the reduced number of red blood cells rather than by the red blood cell size or the amount of hemoglobin (29). Moreover, it has been observed in in vitro studies that describes increasing ROS causes a decrease in the deformability of red blood cells and an increase in their aggregation (2). It was proposed that high oxidative stress causes cardiovascular impairment, but some of these changes depend on the subjects/animals training level. For example, during exercise, the oxidative stress decreases the deformability of blood cells and increases in osmotic fragility in untrained rats but not in trained rats (27). In addition, oxidative stress produced hemolysis in sedentary human subjects, but not in trained ones (28). In this study, untrained rats were used, which were more susceptible to suffer hemolysis induced by the oxidative stress of the ultraendurance race (23); however, a megadose of 5,000 IU/kg $\alpha$-tocopherol prior to the probe seemed to prevent these symptoms of transitory sports anemia, because it allowed to maintain a larger number of red blood cells after exercise and therefore a greater amount of hemoglobin and hematocrit.

Strenuous exercise induces a redistribution of immune cells and a release of mediators similar to an inflammatory response induced by an infection (34). In particular, increasing white blood cell (leukocytosis), more specifically neutrophil and monocyte counts in response to muscle damage, can be observed after ultraendurance probes $(8,36)$. In this study, a larger number of white cells were observed in the group treated with a 5,000 IU/kg $\alpha$-tocopherol megadose than in the other two groups. In this regard, we must remember that the maximum tolerable amount of $\alpha$-tocopherol in adults is $1,500 \mathrm{IU} /$ day $(20 \mathrm{IU} / \mathrm{kg})$. Long-term intake above these doses increases the risk of adverse health effects (18). Similarly, the use of $\alpha$-tocopherol doses higher than $400 \mathrm{IU} /$ day increases all-cause mortality (16). The finding that in case of some variables, we obtained better results in the VEAG than in the VECG group makes us speculate that usage of acute doses could be a better choice regarding health and performance, but future studies should confirm this hypothesis.

It is known that ultraendurance probes produce hemolysis by an increase in free radicals and lipid peroxidation of erythrocyte membranes (26). The hypothesis that $\alpha$-tocopherol would produce a decrease in oxidative stress, a lower erythrocyte membranes lipid peroxidation, and a decrease in the hemolysis symptoms was observed in the VEAG. We observed this $\alpha$-tocopherol buffer capacity against hemolysis principally in the VEAG, but not in the VECG and CG groups. In conclusion, a dose of 5,000 IU/ $\mathrm{kg} \alpha$-tocopherol prior to an ultraendurance probe improves hematological parameters related to transitory sports anemia.

\section{Limitation of the Study}

The principal limitation of the study was the lack of analysis of rat liver samples, since it is known that high $\alpha$-tocopherol doses could damage this organ. As well, the muscle structure could have been analyzed to have a direct measurement of the ultraendurance probe effect on 
muscle structure and the possible protective effect of $\alpha$-tocopherol, since it is an antioxidant and could protect muscle structure against ROS.

\section{REFERENCES}

1. Aguilo A, Tauler P, Fuentespina E, Villa G, Cordova A, Tur JA, Pons A: Antioxidant diet supplementation influences blood iron status in endurance athletes. Int. J. Sport Nutr. Exerc. Metab. 14, 147-160 (2004)

2. Baskurt OK, Meiselman HJ: Hemodynamic effects of red blood cell aggregation. Indian J. Exp. Biol. 45, 25-31 (2007)

3. Berzosa C, Gómez-Trullén EM, Piedrafita E, Cebrián I, Martínez-Ballarín E, Miana-Mena FJ, Fuentes-Broto L, García JJ: Erythrocyte membrane fluidity and indices of plasmatic oxidative damage after acute physical exercise in humans. Eur. J. Appl. Physiol. 111, 1127-1133 (2011)

4. Bompadre S, Leone L, Politi A, Battino M: Improved FIA-ABTS method for antioxidant capacity determination in different biological samples. Free Rad. Res. 38, 831-838 (2004)

5. Clemente-Suárez VJ: Changes in biochemical, strength, flexibility and aerobic capacity parameters after a $1700 \mathrm{~km}$ ultraendurance cycling race. BioMed Res. Int. 2014, 602620 (2014)

6. Hale JP, Winlove CP, Petrov PG: Effect of hydroperoxides on red blood cell membrane mechanical properties. Biophys. J. 101, 1921-1929 (2011)

7. Jenkins RR, Goldfarb A: Introduction: Oxidant stress, aging, and exercise. Med. Sci. Sports Exerc. 25, 210-212 (1993)

8. Kłapcińska B, Waśkiewicz Z, Chrapusta SJ, Sadowska-Krępa E, Czuba M, Langfort J: Metabolic responses to a 48-h ultra-marathon run in middle-aged male amateur runners. Eur. J. Appl. Physiol. 113, 2781-2793 (2013)

9. MacCrehan WA: Determination of retinol, $\alpha$-tocopherol and $\beta$-carotene in serum by liquid chromatography. Methods Enzymol. 189, 172-181 (1990)

10. Marsh SA, Laursen PB, Coombes JS: Effects of antioxidant supplementation and exercise training on erythrocyte antioxidant enzymes. Int. J. Vitam. Nutr. Res. 76, 324-331 (2006)

11. Martín S, Nebot E, Clemente V, Aparicio V, Kapravelou G, Porres J, Urbano G, Aranda P: Eficacia de dos protocolos incrementales hasta alcanzar el $\mathrm{VO}_{2 \max }$ en ratas wistar [Efficiency of two incremental protocols until reaching $\mathrm{VO}_{2 \max }$ in Wistar rats]. Arch. Med. Deporte. 139, 400 (2010)

12. Mastaloudis A, Leonard SW, Traber MG: Oxidative stress in athletes during extreme endurance exercise. Free Radic. Biol. Med. 31, 911-922 (2001)

13. Maughan RJ: Fluid and electrolyte loss and replacement in exercise. J. Sports Sci. 9, 117-142 (1991)

14. McAnulty SR, McAnulty LS, Nieman DC, Morrow JD, Shooter LA, Holmes S, Heward C, Henson DA: Effect of alpha-tocopherol supplementation on plasma homocysteine and oxidative stress in highly trained athletes before and after exhaustive exercise. J. Nutr. Biochem. 16, 530-537 (2005)

15. Merry TL, Ristow M: Do antioxidant supplements interfere with skeletal muscle adaptation to exercise training? J. Physiol. 594, 5135-5147 (2016)

16. Miller ER, Pastor-Barriuso R, Dalal D, Riemersma RA, Appel LJ, Guallar E: Meta-analysis: High-dosage vitamin E supplementation may increase all-cause mortality. Ann. Intern. Med. 142, 37-46 (2005)

17. Miyazaki H, Oh-ishi S, Ookawara T, Kizaki T, Toshinai K, Ha S, Haga S, Ji LL, Ohno H:Strenuous endurance training in humans reduces oxidative stress following exhausting exercise. Eur. J. Appl. Physiol. 84, 1-6 (2001)

18. Monsen ER: Dietary reference intakes for the antioxidant nutrients: Vitamin C, vitamin E, selenium, and carotenoids. J. Am. Diet. Assoc. 100, 637-640 (2000)

19. Mooren FC, Lechtermann A, Volker K: Exercise-induced apoptosis of lymphocytes depends on training status. Med. Sci. Sports Exerc. 36, 1476-1483 (2004)

20. Patil SM, Chaudhuri D, Dhanakshirur GB: Role of alpha-tocopherol in cardiopulmonary fitness in endurance athletes, cyclists. Indian J. Physiol. Pharmacol. 53, 375-379 (2009)

21. Paulsen G, Cumming KT, Holden G, Hallén J, Rønnestad BR, Sveen O, Skaug A, Paur I, Bastani NE, Østgaard HN, Buer C, Midttun M, Freuchen F, Wiig H, Ulseth ET, Garthe I, Blomhoff R, Benestad HB, Raastad T: Vitamin $\mathrm{C}$ and $\mathrm{E}$ supplementation hampers cellular adaptation to endurance training in humans: A double-blind, randomised, controlled trial. J. Physiol. 592, 1887-1901 (2014)

22. Radak Z, Ishihara K, Tekus E, Varga C, Posa A, Balogh L, Boldogh I, Koltai E: Exercise, oxidants, and antioxidants change the shape of the bell-shaped hormesis curve. Redox Biol. 12, 285-290 (2017) 
23. Robinson Y, Cristancho E, Boning D: Intravascular hemolysis and mean red blood cell age in athletes. Med. Sci. Sports Exerc. 38, 480-483 (2006)

24. Rowlands DS, Pearce E, Aboud A, Gillen JB, Gibala MJ, Donato S, Waddington JM, Green JG, Tarnopolsky MA: Oxidative stress, inflammation, and muscle soreness in an 894-km relay trail run. Eur. J. Appl. Physiol. 112, 1839-1848 (2012)

25. Schmidt W, Heinicke K, Rojas J, Manuel Gomez J, Serrato M, Mora M, Wolfarth B, Schmid A, Keul J: Blood volume and hemoglobin mass in endurance athletes from moderate altitude. Med. Sci. Sports Exerc. 34, 1934-1940 (2002)

26. Sentürk UK, Gündüz F, Kuru O, Aktekin MR, Kipmen D, Yalçin O, Bor-Küçükatay M, Yeşilkaya A, Başkurt OK: Exercise-induced oxidative stress affects erythrocytes in sedentary rats but not exercise-trained rats. J. Appl. Physiol. 91, 1999-2004 (2001)

27. Sentürk UK, Gündüz F, Kuru O, Koçer G, Ozkaya YG, Yesilkaya A, Bor-Küçükatay M, Uyüklü M, Yalçin O, Baskurt OK: Exercise-induced oxidative stress leads hemolysis in sedentary but not trained humans. J. Appl. Physiol. 99, 1434-1441 (2005)

28. Smith JA, Kolbuch-Braddon M, Gillam I, Telford RD, Weidemann MJ: Changes in the susceptibility of red blood cells to oxidative and osmotic stress following submaximal exercise. Eur. J. Appl. Physiol. Occup. Physiol. 70, 427-436 (1995)

29. Stäubli M, Roessler B: The mean red cell volume in long distance runners. Eur. J. Appl. Physiol. Occup. Physiol. 55, 49-53 (1986)

30. Taber M, Stevens J: Vitamins C and E: Beneficial effects from a mechanistic perspective. Free Rad. Biol. Med. 51, 1000-1013 (2011)

31. Tain YL, Freshour G, Dikalova A, Griendling K, Baylis C: Vitamin E reduces glomerulosclerosis, restores renal neuronal NOS, and suppresses oxidative stress in the 5/6 nephrectomized rat. Am. J. Physiol. Renal. Physiol. 292, F1404-F1410 (2007)

32. Traber MG: Relationship of vitamin E metabolism and oxidation in exercising human subjects. Br. J. Nutr. 96, S34-S37 (2006)

33. Traber MG, Frei B, Beckman J: Vitamin E revisited: Do new data validate benefits for chronic disease prevention? Curr. Opin. Lipidol. 19, 30-38 (2008)

34. Urso ML, Clarkson PM: Oxidative stress, exercise, and antioxidant supplementation. Toxicology 189, 41-54 (2003)

35. Viitala P, Newhouse I: Vitamin E supplementation, exercise and lipid peroxidation in human participants. Eur. J. Appl. Physiol. 93, 108-115 (2004)

36. Waśkiewicz Z, Kłapcińska B, Sadowska-Krępa E, Czuba M, Kempa K, Kimsa E, Gerasimuk D: Acute metabolic responses to a 24-h ultra-marathon race in male amateur runners. Eur. J. Appl. Physiol. 112, 1679-1688 (2012)

37. Wu H, Chen K, Shee B, Chang H, Huang Y, Yang R: Effects of $24 \mathrm{~h}$ ultra-marathon on biochemical and hematological parameters. World J. Gastroenterol. 10, 2711-2714 (2004)

38. Zembron-Lacny A, Szyszka K, Sobanska B, Pakula R: Prooxidant-antioxidant equilibrium in rowers: Effect of a single dose of vitamin E. J. Sports Med. Phys. Fitness 46, 257-264 (2006) 